\title{
Transformational Leadership and Organizational Change: In The Context of Today's Leader
}

\author{
Muliati Usman ${ }^{\mathrm{a}}$ \\ ${ }^{a}$ Management Department, Faculty of Economics and Business \\ Syiah Kuala University, Darussalam, Banda Aceh, Indonesia \\ Corresponding Author: muliatiusman@yahoo.com
}

To cite this article (APA): Usman, M. (2020). Transformational Leadership and Organizational Change: In The Context of Today's Leader. International Business Education Journal, 13(1), 95-107. https://doi.org/10.37134/ibej.vol13.1.8.2020

To link to this article: https://doi.org/10.37134/ibej.vol13.1.8.2020

\begin{abstract}
Today's leader deals with many challenges in enacting roles as agents of change. Extremely uncertain and rapidly changing in a dynamic environment become a crucial problem for a leader in mobilizing organizational change. It is imperative for a leader to adopt a strategic approach to drive organizational change effectively for establishing organizational improvement and sustainability. This article reviews transformational leadership as an effective model to drive organizational change in the context of today's organization leader. Although, there is still controversy about the significant leadership style for establishing changes, the results of previous studies have proven that transformational leadership is a specific approach to achieve the success of organizational change in today's environment.
\end{abstract}

\section{Keywords:}

Transformational leadership, organizational change, dynamic environment

\section{INTRODUCTION}

It raises issues on the importance of enacting change by today's leader that forces organizations to the need for a visionary and innovative leader of change (Sahu et al., 2018; Laohavichien et al., 2009; Mathews and Linski, 2016; Gilley et al., 2009a). The success of organizational change is a result of leadership in carrying out role as agents of change. Therefore, efforts of a leader in creating change will lead organization to the success in a dynamic environment (see Soane et al. 2015; Yulk, 2010; Nusair et al., 2012; Al-Hussami et al. 2017; Mathews and Linski, 2016). Indeed, it is crucial for organizations to sustain leader who can deal with change effectively due to constant major changes in current environment. A result of the lack of ability in adapting changes will damage organizational performance and often harm extremely the sustainability or existence of an organization (Boga and Ensari, 2009; Owie, 2019). Thus, effective change by the leader presents various efforts to organizational improvement (Self and Schraeder, 2009; Samad, 2012). Besides, leader must struggle to align organization with the current environment to ensure organizational stability (Nusair et al., 2012). Change is inevitable when an organization needs to survive for the sustainability of the organization in the future (Millar et al., 2012; Mathews and Linski, 2016). In other words, organizational change embraces the extent to which leaders overcome the uncertainty through a radical change.

In fact, organizational change and effectively managing all its peculiarities deals with a challenge (Mathews and Linski, 2016; Boga and Ensari, 2009). Organizations need to 
adjust change on the factors in social, cultural, economic, political, demographic (Middleton et al., 2015). Mainly, the eminent aspect related to the reality of the new economy is the inevitability of organizational change to interact efficiently and effectively in the dynamics of local and global environment (Owie, 2019). There are various kinds of changes faced by organizations including changes in the global environment, changes in labor, technological changes, and an increasingly competitive environment, as well as a constantly changing economic environment (Self and Schraeder, 2009). Thus, organizational change becomes an option when it was focused on prudence and a comprehensive understanding of external environment of organization and the organizational dynamics (Boga and Ensari, 2009; Owie, 2019).

A deeper understanding of effective leadership in specific conditions is imperative in the current dynamic environment (Northouse, 2007; Boga and Ensari, 2009). Organizations continuously develop efforts to find approaches that will enable to enhance organizational effectiveness. Leaders of change need to create a conducive environment by pushing members of the organization to collaborate for the process of change that must be carried out by organizations constantly to maintain position in the current environment. Effective leadership will lead organizations in an uncertain environment to adopt a specific approach to determine the strategic direction of the organization (Matzler et al., 2015). A study by Gilley et al. (2009b) found evidence of the importance of specific leadership in the global economy for the success of organizational change since it is a critical approach for today's organizational leader who deals with issues related to the successful implement change. Therefore, it is important to foster effective leadership so that organizational performance can be improved because the lack of the best leadership will weaken the motivation of employees to carry out tasks innovatively and effectively (Nusair et al., 2012).

Whilst, in a contemporary organization, the aspect of reality is the pressure caused by globalization. Environmental complexity and the need for the most effective leaders have called to transformational leadership as a specific approach to drive change (Van der Voet et al., 2016). The competent model of transformational leadership is an appropriate approach that has practical value for global organizations (Boga and Ensari, 2009). Feng et al. (2016) argued that this style of leadership is desirable and necessary because of the competitive environment that forces organizations to be leaders of change to keep change and improve the capacity of organizations to the innovativeness (Matzler et al., 2015; Feng et al., 2016). Thus, managers who develop and maintain transformational leadership can consistently provide navigation to a complex and fast-changing environment (Murphy, 2005).

Organizations managed by transformational leaders are considered more successful in situations of high organizational change than those with low organizational change. The interaction between organizational change and transformational leadership style is an appropriate predictor of organizational success when an organization undergoes high organizational change or many organizational adjustments rather than when the change is low (few organizational adjustments) (Boga and Ensari, 2009). Further, Al-Hussami et al. (2017) mentioned that leaders with transformational competence are agents of change who are more effective, productive, and empower. Transformational leadership will increase the competitiveness of organizations in anticipating a dynamic environment. Therefore, transformational leadership is performed to reach the sustainability of leadership quality. Managers can apply the leadership style to stimulate organizational improvement through transformational leadership (Hirtz et al., 2007; Samad, 2012; Suzyanty Mohd Shokory et al., 2019). 
It is important to be considered that transformational leadership is the most influential theory of leadership in today's environment (Matzler et al., 2015). Transformational leadership received great attention from researchers since it was found to greatly influence leadership practices. There is increasing evidence by the scholars on the role of transformational leadership as an appropriate approach in enhancing organizational change (e.g Van der Voet et al., 2016; Middleton et al. 2015; Mwangi and Kwasira, 2015; Chou, 2014; Busari et al., 2019; Carter et al., 2013; Feng et al., 2016; Howarth and Rafferty, 2009; Holten and Brenner, 2015). According to Yulk (2010), transformational leadership is a specific leadership approach that focuses on the abilities of a leader as a process to change and transform employees through increasing motivation to work, establishing high commitment, and empowering employees in efforts to achieve organizational goals. Leaders must be able to direct followers to actively participate in achieving the leader's vision and be willing to fulfill commitments to accomplish the direction of the leader (Northouse, 2007). Therefore, transformational leadership is the most appropriate approach in the current environment that has a positive impact on employees. It involves a high level of awareness of employees on their role in organizational change. Specifically, it provides an understanding of how is the interaction of transformational leadership and organizational change can affect organizational success in today's environment (Boga and Ensari, 2009).

However, organizational change highly varies, different types of change, of course, require different types of leadership. Although the concept of transformational leadership has been proven in influencing the success of organizational change, there is still a controversial issue regarding the strategic approach of leadership for the efficiency and effectiveness of organizational change in an extremely dynamic environment (Osseo-Asare et al. 2005, Northouse, 2007). Besides, it is a lack of study on a critical issue of transformational leadership in a changing context in current decades (Chou, 2014). Moreover, the disconnect between the intention of organization to run change and the ability of leaders to perform the development of change calls for further investigation (Gilley et al., 2009b). To get a comprehensive understanding of the role of transformational leadership, this study examines the extent to which this leadership approach sustains organizational change among the various challenges that must be faced by today's leader in a dynamic environment. This study argues that transformational leadership is an urgent approach for the current global environment that can be applied to drive organizational change.

\section{TRANSFORMATIONAL LEADERSHIP}

Transformational leadership is a type of visionary leadership initiated by Deming as the most appropriate type of leadership to improve the quality of management (Laohavichien et al., 2009) that was introduced by Burn in 1978 and Bass in 1985. Transformational leadership places on the importance of mission and outcome of organization, emphasizes principles of participatory leadership and emphasizes empowerment and proaction (Middleton et al., 2015). Further, transformational leadership utilizes 4 components i.e. idealized influence (charisma), inspirational motivation, intellectual stimulation, and individualized consideration (Bass and Riggio, 2006). Specifically, Pastor and Mayo (2008) identified: first, the idealized influence or charisma is referring to the ability of a leader to influence followers intensively, then, the leader instills beliefs, attitudes, and behavior to the follower. Therefore, charisma is a relationship or a bond between a leader and a follower. Charismatic leaders articulate goals as a whole, communicate high expectations to followers, and provide trust to build emotional ties with followers. Charismatic leaders create a sense of strength, confidence, and dynamism 
towards the team in the organization. Second, inspiration motivation refers to the behavior of leaders who can motivate and inspire their followers such as by setting challenging goals and tasks to give meaning to the work. Third, intellectual stimulation refers to the behavior of leaders who give confidence to followers by questioning the assumptions of followers and helping them to reframe the problem. Finally, individualized consideration that is the managers provide concern for employee welfare and show acceptance of differences in individuals.

In most organizations, transformational leadership is considered as a more effective leadership approach compared to transactional leadership. Transformational leadership is different from transactional leadership in terms of basic values and beliefs in managing people (Pastor and Mayo, 2008). Transactional leadership guides or motivates followers towards the goals of organization by clarifying the roles and requirements of the task that is based on rewards for accomplishment and punishment for failure. Thus, transactional leadership was presumed more control-oriented. Conversely, transformational leadership enhances the morals and values of followers that inspires followers to act beyond their personal interests for the goals of the organization. As a result, transformational leadership has a tremendous impact on followers (Robbins and Coulter, 2014). It looks to satisfy and increase the needs of his followers by engaging his followers fully. Therefore this leadership was more complex and effective than transactional leadership.

It can be identified that transformational leadership is more dynamic than transactional leadership that is more static or rigid. A study by Musa (2014) revealed that transformational leadership has a significant impact on the commitment of teachers. While there is no significant impact of transactional leadership on the commitment of teachers. Thus, transformational leadership is an appropriate approach of leadership compared to transactional leadership. Efforts and investments toward the development of transformational leadership for top management will result in management leadership that will improve higher performance. It will result in a positive performance for the organization as a whole (Hirtz et al., 2007). Transformational leadership requires leaders who can develop and articulate a shared vision that motivates, inspires, and challenges followers (Matzler et al., 2015). As Pastor and Mayo's research (2009) showed, the development of transformational leadership requires people to act by considering the values and beliefs that exist in the leader. This leader tends to enjoy new and difficult tasks. They value learning opportunities based on thinking that abilities can be further enhanced. The most important is that transformational leadership can motivate their subordinates to commit themselves to organizational success. Conversely, transactional leadership is more likely to think that ability is permanent or cannot be upgraded. At work, they prefer routine tasks that are already known.

Further, to achieve the effectiveness of transformational leadership, it should be considered the influence of the organization and followers. It is clear, to deal effectively with change, leaders must be able to direct followers to actively participate in achieving the leader's vision and be willing to fulfill commitments to accomplish the direction of the leader (Northouse, 2007). According to Brymer and Gray (2006), transformational leadership is essential because it provides a model for those who apply leadership which is highly dependent on skills and behavior that is determined by situations where self-development and others are a priority. The results of study by Ho (2016) indicated that transformational leadership can significantly increase employee job satisfaction and increase commitment to the organization. Leaders need to understand the contextual factors that influence commitment and job satisfaction of followers. Thus, leaders need to provide an understanding 
of the vision, consideration, and intellectual stimulation of followers. Leaders must also prepare detailed work rules, policies, guidelines, and procedures. Then to maintain team cohesiveness among subordinates, leaders must work to eliminate conflicts between followers. According to Samsudin et al. (2017), management support and the relationship between leader and member will increase trustworthiness that can develop an adequate environment and improve organizational climate. This evidence is in line with the opinion by Murphy (2005), transformation leadership requires numerous attributes and also requires conditions to influence the quality of its success.

\section{ORGANIZATIONAL CHANGE}

Changes in organizations can be interpreted in depth when noticed from an evolutionary perspective which is transitional, transformational, or developmental. Generally, improving the current situation is implemented through transitional or minor changes. The transition of change improves the current situation through gradual changes in people, structures, procedures or technology. The changes that are driven by management in this organization are to enable the organization to be better in what it does (Gilley et al., 2009b). There are 3 steps of change implementation process. First, communicating: emphasize the communication activities among members of organization for the change including critical aspect to communicate vision, emphasize the need for change, communicate ideas effectively behind the change, and devote significant time and energy to develop a vision for the outcome of organizational change. Second, mobilizing: emphasize on the activities of leader to mobilize process of change: sought others in organization to help in shaping the vision of organization, consider help and input of others, seek input of various stakeholder in smoothing way to introduce change, redesign process and system of organization to change. Finally, evaluating: emphasize on the evaluation activities comprising utilized a formal system of measurement to evaluate the effect of change and utilize a formal system of measurement to evaluate the need for refinements the way the change was implemented in the organization (Battilana et al., 2010).

Leadership in the current environment cannot avoid the effect of change. However, resistance to change remains an essential topic in organizations given that the dynamic nature of the world today requires organizations to be adaptive on change (Mathews and Linski, 2016). Resistance to change is a problem that must be resolved. What needs to be done is to change the paradigm of rejection into a new paradigm that can help organizations better prevent and overcome behavior that rejects these changes and not just avoid change (Gilley et al., 2009b). Organizational change needs a high contribution and commitment of organization members as actors who will run changes in the organization. Indeed, organizations will face people who are resistant to change. Besides the benefits of organizational change, there are unintended consequences as a result of organizational change. It is certainly related to the relationship between echelons in the organization and the strengthening of polarization. On one side, the leader is the one who visualizes and manages the changes. On the other side, employees are people who have to do and embrace these transformations or changes. Predictably, the change actions will cause anxiety and pressure among employees. It also triggers negative perceptions of the organization in general. Then, in the end, it will harm the organization hinders the progress to be achieved by the change (Boga and Ensari, 2009).

Further, Gilley et al. (2009a) asserted that the business field is still to meet leaders who do not have the requisite skills. To drive change, effective leaders have become to fully 
engage employees to foster success in dealing with an organization that is constantly and rapidly changing in the face of dynamic and global environments. As a result, deployment interpersonal skills lead to effective leading to change. To gain trust as a credible leader, and to reduce resistance to changes by members of the organization, the leader must be directly involved in the essence of change, attend training with employees, listen to the thoughts and comments of employees and serve employees as a mentor when there is a dispute (Self and Schraeder, 2009). The results of the study by Gilley et al. (2009a) asserted the importance of interpersonal value skill to success in implementing change. Specifically, it was determined by the ability to motivate, communicate, and creating an environment that supports the team. Leaders who choose and can show these skills are perceived to be more effective in driving change. Thus, it is important to shift the paradigm by evaluating organizational changes that can include a variety of transformations or changes of employees including how to supervise employees, way of work, communicate, and also how they relate to each other (Mathews and Linski, 2016). Thus, to deal with employee resistance to change, leaders must engage employees and encourage their active participation and strengthen employee confidence in their potential to feel vulnerability and alienation during organizational change or transformation (Boga and Ensari, 2009).

\section{TRANSFORMATIONAL LEADERSHIP AND ORGANIZATIONAL CHANGE}

It is important for leaders to arrange an approach that allows for organizational change (Mathews and Linski, 2016). Transformational leadership is an effective leadership approach to enhance positive appraisal change of followers. This leadership style has long-term and short-term positive effects, directly and indirectly. Improving the transformational potential of managers will provide benefits in the whole process of change. The leader's direct involvement in change is associated with followers' change appraisal. Thus, awareness of the leader's role in working actively and positively to change is a positive investment in the organization in implementing change (Holten and Brenner, 2015). More specifically, transformational leaders have such a great influence on their followers. These leaders pay individual consideration to the individual as the subordinate, thinking about various possibilities in the future and acting self-sacrificially. Therefore, the development of values and belief in transformational leadership will be beneficial for the long-term development of transformational leadership. When transformational leaders have supportive behavior that is unique to their subordinates, then this will have an extraordinary impact on followers. These values and beliefs stimulate followers, then they are motivated to learn and grow towards ideological goals. Likewise with transformational leaders, they will be able to invest time and various efforts in developing followers because they believe that the competencies can be stimulated and developed.

Organizational change requires a change of thinking and attitude that usually started by the leadership (Millar et al., 2012). Therefore, transformational leadership can be realized when subordinates find a balance of personal identification with the goal of the leader so that followers voluntarily are willing to put forth a high effort and commitment in the effort to achieve organizational goals (Pastor and Mayo, 2008; Suzyanty Mohd Shokory et al., 2019). Yet, researchers have a different perspective on the important effect of transformational leadership on organizational change. There are still researchers that question the effectiveness of transformational leadership style and attempt to compare between transactional leadership and transformational leadership. A study by Adserias et al. (2017) failed to reveal that transformational leadership is the best leadership style in organizational change. They 
examined which style of leadership is appropriate in higher education to direct organizational change to fuel institutional diversity. The result of study found, there is no most suitable leadership style to be applied in organizational change to implement diversity in higher education. The best way is to use both leadership styles, namely transactional leadership, and transformational leadership. This result is different from the results of research generally that have succeeded in proving that transformational leadership plays a very important role in determining the success of organizational change. In contrast, Brymer, and Gray (2006) is successful in examining that transformational leadership is an appropriate leadership style compared to transactional leadership. Because of the effect of a rapidly changing environment, effective outdoor leadership needs leaders with a transformational leadership approach. Leaders have to consider certain situational and establish appropriate behavior by using a transformational leadership approach. Thus, transformational leadership is ideal implemented in a specific environment.

However, scholars have formulated the strategic role of transformational leadership in organizational change. Transformational leadership was proven encouraging organizational change in various fields such as education, management, health, leisure, social service, military, etc. Transformational leadership also encourages organizational change in all types of organizations (i.e. private, public, or government and non-profit organization). A study by Chou (2015) examined the effect of transformational leadership on organizational change in various settings among 10 organizations in Taiwan: five manufacturing companies, one auto sales office, one association of farmer, one insurance company, and the last one company of security. The research found that transformational leadership has a positive impact on supportive behavior of followers for organizational change. Transformational leadership has a function as a means of decrease stress of employee by improving self-efficacy of employee that in turn in increase affective commitment to change, and promote behavioral support for change. Therefore, transformational leadership can enhance organizational change through employees' behavioral support.

While, Basham (2012) revealed that transformational leadership in higher education as an effective approach for today's leader to support organizational change. The study found the positive effect of utilizing transformational leadership practice to drive change through its characteristics. Transformational leadership generates trust of the follower. By using transformational leadership, higher education can develop a vision and designed strategy well to face significant change by energizing all members of organization. Furthermore, Middleton et al. (2015) conducted qualitative study to investigate the effect of transformational leadership approach to organizational change in the human service field. They found the impact of transformational leadership on employee engagement on organizational change through many elements of transformational leadership i.e. inspiration, optimism, encouragement, honesty, motivation, respect, team-orientation, effective communications, empowerment, reliability, trustworthiness, and empathy. This result emphasized that transformational leadership on organizational change is the most important approach to be implemented in the human service organization to facilitate organizational change effectively in dynamic organizations.

Although the complex environment and formal organizational structure in public sector as a contradiction on the role of manager as a change leader, transformational leadership in public or government organizations also play an important role in influencing organizational change. It was revealed by Van der Voet et al. (2016) that transformational leadership is specific characteristics in the public sector that influence process and 
commitment to change of organizational member. The role of transformational leadership is central in organizational change of public sector that contributes to the successful implementation of change. Further, Mwangi and Kwasira (2015) found the positive effect of transformational leadership on organizational change in public secondary schools. The result of the study revealed that transformational leadership has a positive impact on organizational change. It is the inspirational leadership that boost motivation of the teachers and principals in the implementation of change. Moreover, the study by Seo et al. (2012) was conducted in the government agency in the field of transportation. They found evidence that transformational leadership positively related to the positive behavior of employees that in turn greater commitment to change as well as to more creative, supportive and less employee resistance during organizational change. While, Harb and Sidani (2019) conducted the study by using a semi-focused interview with 10 leaders of public sector. The result of the study found that transformational leadership influences the successful implementation of organizational change. It is important as an effective approach for leaders in promoting change in the public sector through idealized influence and inspirational motivation.

Furthermore, as a comparison between private and government sector, Min-xin and Li-rong (2007) explored the linking between transformational leadership and organizational change by including 33 Chinese construction enterprises in private and state-owned. They found that transformational leadership accelerates organizational change and innovation in construction enterprises both in private and government sector. The finding indicated that transformational leadership has a positive effect on each dimension of organizational change that includes employees' appraisal, elements such as a product or service, technology, people and task, size of organization, and pace of organization. Effective transformational leadership can reduce resistance of employees on change, provide favorable elements, lead organization to choose adaptive size of organization and improve pace of organizational change.

Indeed, transformational leadership has a comprehensive impact on organizational change in various ways. Besides transformational leadership as an antecedent of organizational change, it can be found that transformational leadership encourages a culture of innovation that is necessary for organizations in today's environment. Implementation of transformational leadership can boost organization to the innovation. It is important to note that transformational leadership produces a dynamic organizational vision that involves cultural values so that it reflects innovation with a greater quantity. Thus, organizational member readiness for change involves the culture and structure of the organization (Self and Schraeder, 2009). Transformational leadership shapes the culture of innovation within the organizational environment through the values instilled by leaders. It is not surprising when scholars found the effect of transformational leadership in the process of organizational change by using the practice of innovation (see Michaelis et al., 2010; Hu et al., 2013; Nusair et al., 2012; Sattayaraksa and Boon-itt, 2018). Thus, Hu et al. (2013) confirmed that although the conclusions drawn from different studies are somewhat inconsistent, most scholars found a positive relationship between transformational leadership and organizational creativity and innovation. Transformational leadership can boost directly and indirectly creativity and innovation of an organization. The bulk of this paper is about the indirect effects of transformational leadership. The mediators and moderators are from different levels including individual, team, and organizational levels. Besides, some contextual variables are also included.

Furthermore, the frequency of changes is also a factor that must be considered in the organization. Constant adaptation of new behavior has the potential effect to negatively 
influence employee attitudes toward change. In these circumstances, transformational leadership has a high potential to bring up unfavorable perceptions from employees of organizational change and thus adversely affect organizational success (Boga and Ensari, 2009). Hu et al. (2012) claimed that an important characteristic of transformational leaders is that they intellectually encourage employees to contribute ideas and suggestions (intellectual stimulation). These leaders are motivated to look for new challenges and find new ways of doing work. So it can be considered they are sensitive to the contribution of followers. AlHussami et al. (2017) expressed that characteristics of transformational leadership styles can be developed to organizational employees by using the assumption that these characteristics in transformational leadership will have an impact on employee readiness to change.

\section{CONCLUSION}

It is urgent to empower a leader to boost organizational change in today's competitive global environment. Transformational leadership is an appropriate model in a dynamic environment to face constant change. As claimed by Self and Schraeder (2009), effective planning and management of the change process are not impossible to realize. Through an appropriate change strategy, it is possible for leaders of an organization to increase the likelihood of success in implementing change. Therefore, Sahu et al. (2018) proposed that transformational leadership is an appropriate approach among other leadership styles to fit the requisition to the innovative leader for organizational change. Meanwhile, the interaction between transformational leadership and organizational change also has a strong effect on organizational outcomes. This relationship has fostered followers to a strong culture of innovation. Leaders mobilize followers on readiness for change by encouraging the creation of novel ideas. As confirmed by Michaelis, et al. (2010); Hu et al. (2013), transformational leadership is inherent naturally in innovative behavior that leads followers to the commitment to change. However, the negative and deficiency approach used to deal with employee resistance to change seems to be contradictory. It is necessary to learn how to overcome resistance positively so that it can implement change successfully (Mathews and Linski, 2016).

It is important to note that there will be challenges in the form of rejection of changes from members of organization on the implementation of transformational leadership to encourage organizational change. Therefore, in a current dynamic environment, leaders must understand how this transformational approach will be able to overcome obstacles in implementing change so that rejection can be overcome by giving followers awareness. Leaders and employees in organizations need to be built up to participate in the process of change in their organizations. Organizations and employees also have the same interests that must be achieved so that followers will voluntarily engage in change. The best way is to focus on human resources as the capital asset for successful organizational change. As stated by Busari et al. (2019), the successful implementation of change in organizations is determined by employees as followers and leaders with transformational leadership behavior. They play an important role in shaping positive reactions to changes in the organization. Followers contribute to the role of leaders in the process of change.

However, the success of transformational leadership requires maximum efforts. As stated by Murphy (2005), transformational leadership uses as a new criterion for managers that can be achieved through training, education, and professional development activities. Howarth and Rafferty (2009) argued that organizations will get the benefit of training on the 
manager. It will provide specific guidelines for leaders to lead and manage change successfully in more complex, fast, and turbulence change. Training is the most effective way to empower the manager to cultivate support of employees for change. Therefore, emphasizing training, education, and development activities to the managers is important activity to lead leaders to become more competent in mange change in dynamism.

\section{REFERENCES}

Adserias, R. P., Charleston, L. J., \& Jackson, J. F. (2017). What style of leadership is best suited to direct organizational change to fuel institutional diversity in higher education?. Race Ethnicity and Education, 20(3), 315-331.

Al-Hussami, M., Hamad, S., Darawad, M., \& Maharmeh, M. (2017). The effects of leadership competencies and quality of work on the perceived readiness for organizational change among nurse managers. Leadership in Health Services, 30(4), 443-456.

Basham, L. M. (2012). Transformational leadership characteristics necessary for todays leaders in higher education. Journal of International Education Research (JIER), 8(4), 343-348.

Boga, I., \& Ensari, N. (2009). The role of transformational leadership and organizational change on perceived organizational success. The Psychologist-Manager Journal, 12(4), 235-251.

Bass, B. M., and R. E. Riggio (2006). Transformational Leadership.(2 ${ }^{\text {nd }}$ Edition) Mahwah, NJ: Lawrence Erlbaum Associates.

Battilana, J., Gilmartin, M., Sengul, M., Pache, A. C., \& Alexander, J. A. (2010). Leadership competencies for implementing planned organizational change. The leadership Quarterly, 21(3), 422-438.

Brymer, E., \& Gray, T. (2006). Effective leadership: Transformational or transactional?. Journal of Outdoor and Environmental Education, 10(2), 13-19.

Busari, A. H., Khan, S. N., Abdullah, S. M., \& Mughal, Y. H. (2019). Transformational leadership style, followership, and factors of employees' reactions towards organizational change. Journal of Asia Business Studies, 14(2), 181-209.

Carter, M. Z., Armenakis, A. A., Feild, H. S., \& Mossholder, K. W. (2013). Transformational leadership, relationship quality, and employee performance during continuous incremental organizational change. Journal of Organizational Behavior, 34(7), 942958.

Chou, P. (2015). Transformational leadership and employee's behavioral support for organizational change. European Journal of Business and Management, 7(3), 110-122.

Feng, C., Huang, X., \& Zhang, L. (2016). A multilevel study of transformational leadership, dual organizational change and innovative behavior in groups. Journal of Organizational Change Management, 29(6), 855-877. 
Gilley, A., McMillan, H. S., \& Gilley, J. W. (2009a). Organizational change and characteristics of leadership effectiveness. Journal of Leadership \& Organizational Studies, 16(1), 38-47.

Gilley, A., Gilley, J. W., \& McMillan, H. S. (2009b). Organizational change: Motivation, communication, and leadership effectiveness. Performance Improvement Quarterly, 21(4), 75-94.

Harb, B., \& Sidani, D. (2019). Transformational leadership for organizational change in the Lebanese public sector. Problems and Perspectives in Management, 17(2), 205-216.

Hirtz, P. D., Murray, S. L., \& Riordan, C. A. (2007). The effects of leadership on quality. Engineering Management Journal, 19(1), 22-27.

Ho, J. (2016). Influence of organizational context and follower's deposition on the effectiveness of transformational leadership. International Journal of Organization Theory and Behavior, 19(3), 308-343.

Holten, A. L., \& Brenner, S. O. (2015). Leadership style and the process of organizational change. Leadership \& Organization Development Journal, 36(1), 2-16.

Howarth, M. D., \& Rafferty, A. E. (2009). Transformational leadership and organizational change: the impact of vision content and delivery. Academy of Management, 1, 1-6.

Hu, H., Gu, Q., \& Chen, J. (2013). How and when does transformational leadership affect organizational creativity and innovation?: Critical review and future directions. Nankai Business Review International, 4(2), 147-166.

Hu, J., Wang, Z., Liden, R. C., \& Sun, J. (2012). The influence of leader core self-evaluation on follower reports of transformational leadership. The Leadership Quarterly, 23(5), 860-868.

Laohavichien, T., Fredendall, L. D., \& Cantrell, R. S. (2009). The effects of transformational and transactional leadership on quality improvement. Quality Management Journal, $16(2), 7-24$.

Matzler, K., Bauer, F. A., \& Mooradian, T. A. (2015). Self-esteem and transformational leadership. Journal of Managerial Psychology, 30(7), 815-831.

Mathews, B., \& Linski, C. M. (2016). Shifting the paradigm: reevaluating resistance to organizational change. Journal of Organizational Change Management, 29(6), 963972.

Michaelis, B., Stegmaier, R., \& Sonntag, K. (2010). Shedding light on followers' innovation implementation behavior. Journal of Managerial Psychology, 25(4), 408-429.

Middleton, J., Harvey, S., \& Esaki, N. (2015). Transformational leadership and organizational change: how do leaders approach trauma-informed organizational change... twice?. Families in Society, 96(3), 155-163. 
Millar, C., Hind, P., \& Magala, S. (2012). Sustainability and the need for change: organisational change and transformational vision. Journal of Organizational Change Management, 25(4), 489-500.

Min-xin, M., \& Li-rong, L. (2007). Influence of transformational leadership on organizational change: An empirical study of chinese construction enterprises. IEEE, 1505-1510.

Murphy, L. (2005). Transformational leadership: a cascading chain reaction. Journal of Nursing Management, 13(2), 128-136.

Musa, K. (2014). Study of transformational leadership and teacher commitment in public school reform. International Business Education Journal (Ibej), 7, 31-45.

Mwangi, S. N., \& Kwasira, J. (2015). Role of transformational leadership on organizational change in selected public secondary schools in Nakuru north sub county, Kenya. International Journal of Economics, Commerce and Management, 3(6), 362-372.

Nusair, N., Ababneh, R., \& Bae, Y. K. (2012). The impact of transformational leadership style on innovation as perceived by public employees in Jordan. International Journal of Commerce and Management, 22(3), 182-201.

Northouse, P. (2007), Leadership: Theory and Practice ( $4^{\text {th }}$ ed.). Sage, Thousand Oaks, CA.

Osseo-Asare, A. E., Longbottom, D., \& Murphy, W. D. (2005). Leadership best practices for sustaining quality in UK higher education from the perspective of the EFQM Excellence Model. Quality Assurance in Education, 13(2), 148-170.

Owie, E. T. (2019). Organizational change and improved performance: The role of transformational leadership. Humanities, Management, Arts, Education \& the Social Science, 7(4), 1-8.

Pastor, J. C., \& Mayo, M. (2008). Transformational leadership among Spanish upper echelons. Leadership \& Organization Development Journal, 29(4), 340-358.

Sahu, S., Pathardikar, A., \& Kumar, A. (2018). Transformational leadership and turnover: Mediating effects of employee engagement, employer branding, and psychological. Leadership \& Organization Development Journal, 39(1), 82-99.

Samad, S. (2012). The influence of innovation and transformational leadership on organizational performance. Procedia-Social and Behavioral Sciences, 57, 486-493.

Samsudin, N., Razak, A. Z. A. A., Jalil, N. A., Wahid, H. A., \& Yaakub, K. B. (2017). Transformational leadership practices among academic administrators at a public university in Malaysia. International Business Education Journal (Ibej), 10, 53-62.

Sattayaraksa, T., \& Boon-itt, S. (2018). The roles of CEO transformational leadership and organizational factors on product innovation performance. European Journal of Innovation Management, 21(2), 227-249. 
Self, D. R., \& Schraeder, M. (2009). Enhancing the success of organizational change. Leadership \& Organization Development Journal, 30(2), 167-182.

Seo, M. G., Taylor, M. S., Hill, N. S., Zhang, X., Tesluk, P. E., \& Lorinkova, N. M. (2012). The role of affect and leadership during organizational change. Personnel Psychology, 65(1), 121-165.

Soane, E., Butler, C., \& Stanton, E. (2015). Followers' personality, transformational leadership and performance. Sport, Business and Management: An International Journal, 5(1), 65-78.

Suzyanty Mohd Skohory, Suriani Abdul Hamid, Marinah Awang, \& Norlaile Salleh Hudin (2019). The impact of the leadership of the Head of Department on administrative staff's performance in Malaysian premier education university. International Journal of Academic Research in Business and Social Sciences, 9(3), 27-42.

Robbins, S. P., \& Coulter, M. (2014). Management (12 ${ }^{\text {th }}$ Edition). Pearson Prentice Hall International Edition

Yulk, G.A. (2010). Leadership in Organizations (7th ed.). Prentice Hall, Upper Saddle River, NJ.

Van der Voet, J., Kuipers, B. S., \& Groeneveld, S. (2016). Implementing change in public organizations: The relationship between leadership and affective commitment to change in a public sector context. Public Management Review, 18(6), 842-865. 